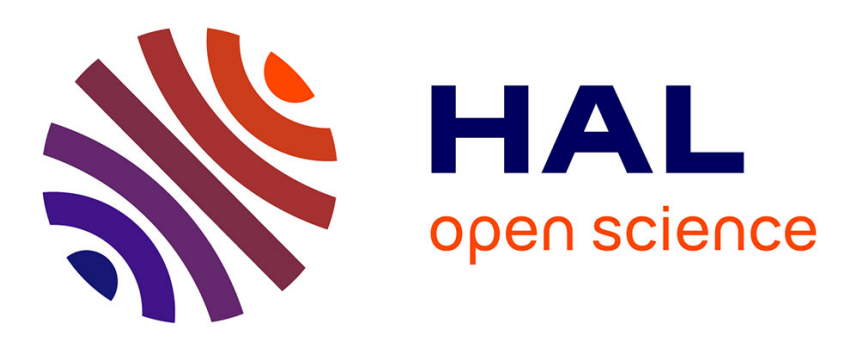

\title{
Grain-size-sensitive flow and shear-stress enhancement at the brittle-ductile transition of the continental crust
}

Frédéric Gueydan, Yves Leroy, Laurent Jolivet

\section{To cite this version:}

Frédéric Gueydan, Yves Leroy, Laurent Jolivet. Grain-size-sensitive flow and shear-stress enhancement at the brittle-ductile transition of the continental crust. International Journal of Earth Sciences, 2001, 90 (1), pp.181-196. 10.1007/s005310000160 . hal-00111342

\section{HAL Id: hal-00111342 \\ https://hal.science/hal-00111342}

Submitted on 3 May 2020

HAL is a multi-disciplinary open access archive for the deposit and dissemination of scientific research documents, whether they are published or not. The documents may come from teaching and research institutions in France or abroad, or from public or private research centers.
L'archive ouverte pluridisciplinaire HAL, est destinée au dépôt et à la diffusion de documents scientifiques de niveau recherche, publiés ou non, émanant des établissements d'enseignement et de recherche français ou étrangers, des laboratoires publics ou privés. 
Frédéric Gueydan • Yves M. Leroy • Laurent Jolivet

\section{Grain-size-sensitive flow and shear-stress enhancement at the brittle-ductile transition of the continental crust}

\begin{abstract}
Localized shear zones along low-angle normal faults have been identified in regions of extension at the brittle-ductile transition of the continental crust. The possibility of the strain localizing at a depth of $10 \mathrm{~km}$ is interpreted here as a consequence of an increase in the equivalent shear stress applied to the flow of the lower crust. This enhancement of the flow stress is seen as a prerequisite for the triggering of brittle deformation mechanisms leading to strain localization. The lower crust rheology used to examine this stress increase is strain-rate, temperature and grainsize dependent, due to the coupling of dislocation and diffusion creep. The model structure proposed consists of a top layer, the upper crust, gliding rigidly above a bottom layer, the lower crust, which deforms in simple shear. During a short time interval (1400 years), the equivalent shear stress is found to increase by a factor of up to 3 (67 MPa for anorthite and $17 \mathrm{MPa}$ for quartz). For anorthite, this stress could explain the activation of a Mohr-Coulomb failure with a friction coefficient of 0.2 , which is reasonable at the depth of $10 \mathrm{~km}$. Dislocation creep is activated during a rapid change in the prescribed velocity, whereas diffusion creep dominates if the velocity is held constant, highlighting the importance of grain-size sensitivity for lower crustal rheology.
\end{abstract}

Keywords Metamorphic core complexes - Continental lower crust · Grain-size-sensitive rheology $\cdot$ Shear

F. Gueydan ( ) Y.M. Leroy

Laboratoire de Mécanique des Solides, Ecole polytechnique, U.M.R. C.N.R.S. no. 7649, 91128 Palaiseau Cedex, France

E-mail: frederic.gueydan@lgs.jussieu.fr

Phone: +33-1-44275943

Fax: $+33-1-44275085$

F. Gueydan · L. Jolivet

Laboratoire de Tectonique, Université P. \& M. Curie, E.S.A. C.N.R.S. no. 7072, T26E1, Case 129, 4 place Jussieu 75252 Paris Cedex 05, France zones $\cdot$ Shear stress enhancement $\cdot$ Brittle deformation mechanisms $\cdot$ Finite-element method

\section{Introduction}

Shear zones that develop at the brittle-ductile transition of the continental crust must require a sufficiently large equivalent shear stress to activate the brittle deformation mechanisms which are thought to be responsible for causing the strain to localize. This shear stress enhancement has to remain compatible with the flow of the lower crust material. To examine this increase during an extension of the crust we focus our attention on the thermo-mechanical response of a 1-D model of the lower crust using the finite-element method.

Wernicke (1985) suggested that normal faults in the upper crust extend into shear zones in the lower crust as well as into the lithospheric mantle. These shear zones should be seen as the precursor of detachment faults which are part of the mechanism responsible for exhumation of metamorphic core complexes (Lister and Davis 1989). The stress state necessary for the onset of a detachment fault at the brittle-ductile transition should be explained to a first-order approximation by a Mohr-Coulomb failure criterion. A fault is generated if the equivalent shear stress is of the same magnitude as the normal stress, assumed to be of the order of the lithostatic pressure, multiplied by a friction coefficient, which typically has values between 0.6 and 1.0 (Byerlee 1978). The objective of this paper is to estimate whether the ductile flow within the lower crust could permit an increase in the equivalent shear stress to the magnitude necessary for brittle mechanisms to be activated, leading to localized shear zones and ultimately to the detachment plane.

This question of the stress state at the brittle-ductile transition was not addressed in earlier works on the existence of a low-angle normal fault. Melosh 
(1990), for example, aimed to capture the orientation of the low-angle normal fault extending from the upper crust to the lower crust but no criterion for fault initiation was examined. A viscous rheology for the lower crust was assumed and the principal stress direction of the evolving flow defined the path of the fault extension. To improve on these results and to capture the position of the fault at its onset, one should postulate some conditions for the activation of the brittle mechanisms responsible for faulting. As a first step in this direction, this paper asks whether the equivalent shear stress could increase sufficiently to trigger brittle deformation mechanisms, using a simple model structure in which an overall simple shear mode of deformation (Couette flow) is considered.

The study of the shear Couette flow for strain-rate and temperature-sensitive materials under steady-state conditions has received the attention of various research communities (see the review in Leroy and Molinari 1992). For example, the existence of a maximum shear stress at a critical velocity applied at the boundary had already been reported by Haag (1944), based on his experimental results on lubricating films. The stress-velocity relation is, for sufficiently small velocities, an increasing function due to the strain-rate sensitivity of the material. The temperature dependence leads to an apparent softening which is responsible for a maximum in the stress-velocity relation being reached at a certain critical velocity. The implications for the stability of the steady flow, which could be inferred from the theoretical work of Joseph (1964), are summarized as follows. The steady states with a boundary velocity smaller than the critical velocity are always stable and are called subcritical. The steady states with a velocity at the boundary greater than the critical value are only stable in a velocity-controlled set-up and are called supercritical. For geological conditions relevant to the asthenosphere, thermal instabilities can therefore occur in the supercritical domain if the relevant boundary condition is stress control (Yuen and Schubert 1977; Schubert and Yuen 1978; see also the review by Brun and Cobbold 1980). The relevant boundary conditions for the mantle are likely to be neither a velocity nor a stress control (Yuen and Schubert 1977). This idea led Melosh (1976) to propose a mixed boundary condition defined as a linear combination between stress and velocity for the stability analysis of the steady states. For the lower crust, the temperature conditions are of course completely different from those in the asthenosphere, so the thermal runaway due to shear heating which could result from an instability of the steady flow is not relevant. Thermal softening is only expected to dominate at the temperatures necessary for phase transformation or dehydration reactions in minerals (Poirier 1980). However, the structure of the stress-velocity relation described above remains applicable to our problem and the question addressed is whether transient effects resulting from a rapid vari- ation in the velocity at the boundary could lead to an increase in the magnitude of the equivalent shear stress far above the maximum value predicted by the steady states. This maximum is strongly dependent on the details of the constitutive model adopted and on the softening deformation mechanisms which are now discussed.

Kirby (1985) identified a number of physical mechanisms which could be responsible for ductile faulting in the lower crust, including dynamic recrystallization. He also emphasized the role of ductile strain localization in metamorphic rocks. Rutter and Brodie (1995) argued that these shear zones are characterized by an intense reduction in grain size. Hopper and Buck (1993) documented the role of diffusion creep (grain-size sensitive rheology) in the upper mantle in the initiation of rifting. The competing effects between grain growth, which inhibits the development of shear zones in the mantle, and grain-size reduction, associated with viscous heating and dynamic recrystallization, were illustrated in a 1-D numerical analysis by Kameyama et al. (1997) and also by Braun et al. (1999).

It is proposed here to test the importance of grainsize sensitivity in the lower crust rheology in defining the magnitude of the equivalent shear stress during a rapid change in extension rate of the upper crust. A simple structural model of a continental crust in extension is proposed, motivated by a review of the tectonics of metamorphic core complexes. The model consists of two layers of horizontal infinite extent, representing the upper crust and the lower crust. Due to the activation of conjugate normal faults, the upper crust is assumed to glide rigidly over the lower crust, the two layers having the same velocity on their plane of contact. The rheology adopted for the lower crust is strain-rate, temperature and grain-size sensitive. Two data sets are considered, the first for quartz and the second for anorthite.

In this paper the next section pertains to a review of the tectonics of core complexes to explain the geometry and loading of our model structure. The constitutive relations adopted for the lower crust material form the core of the section on 'The model problem'. The association in series of the two deformation mechanisms, dislocation and diffusion creep, leads to shear stress enhancement by at least a factor of 3 when the velocity at the brittle-ductile transition is changed by a factor of 10 . This enhancement leads to values for shear stress compatible with a MohrCoulomb failure criterion with a friction coefficient set to the low value of 0.2 . These results are documented in the section on 'Numerical results'.

\section{Model structure of the continental crust in extension}

The objective of this section is to review our common understanding of metamorphic core complexes to jus- 
tify the simple model of the continental crust in extension, studied in the next section.

Detachment faults in metamorphic core complex regions

In Basin and Range metamorphic core complexes (USA), Wernicke (1981) highlights the possibility of a large-scale simple shearing of the lithosphere, leading to the formation of a low-dipping detachment fault. This fault (Wernicke and Burchfiel 1982) downcuts the whole lithosphere and thus partitions it into two regions with a narrow transition zone. This decoupling could explain the prevalence of a simple shear mode of deformation along large-scale ductile shear zones, at a depth close to $10 \mathrm{~km}$ (Davis 1983). These shear zones, characterized by fine-grained microbreccia, evolve towards a decollement plane in the upper layers. This model of large-scale simple shear has also been used to explain geological observations in the Aegean sea (Greece, Lister et al. 1984). During extension, high pressure-low temperature (HP-LT) metamorphic rocks were first non-coaxially deformed along these ductile shear bands and then dragged out brittlely along the detachment fault. We depart slightly from this partition of ductile versus brittle deformations in this paper since we evoke brittle deformation mechanisms at a very early stage of the shearing process in the lower crust to explain the tendency for the detachment plane generation.

According to Lister and Davis (1989) the brittleductile transition plays a key role, due to the introduction of a maximum strength, in detachment faulting. Below this transition, a flat ductile shear zone decouples the upper crust from the deep lower crust where detachment normal faults are rooted. Lister and Davis (1989) thus rejected pure shear as the only mode of deformation for the continental crust in extension and advocated the existence of simple shear at mid-crustal level and pure shear in the deep lower crust. For example, the Snake Range detachment fault (Basin and Range province, USA, Miller et al. 1983) represents a subhorizontal decoupling between the brittle upper crust, deforming by normal faulting, and the uniformly stretched lower crust (see the synthesis proposed by Wernicke 1992). These explanations are confirmed by the observation of a flat-lying Moho in regions of intracontinental extension, and are however in contradiction with the idea of large-scale detachment dowcutting the whole crust (Wernicke and Burchfiel 1982).

Low-angle normal faulting occurring at the brittleductile transition is also suggested by microseismic studies made in regions of active extension. Below the Gulf of Corinth, Greece, microseismic clusters (magnitude between 0.1 and 0.3 ) are observed at a depth between 6 and $11 \mathrm{~km}$ (Rigo et al. 1996). The focal mechanisms correspond to the activation of E-W nor- mal faults. Most earthquakes are aligned along a lowdipping plane and nodal planes are dipping $10-25^{\circ}$ to the north, leading to the recognition of a deep detachment fault in which high angle normal faults of the upper crust are rooted. A similar pattern is observed towards the north, in the North Aegean Trough and Thermaïkos basin (Greece, Laigle et al. 2000).

The island of Tinos, located in the north-western Cyclades archipelago, Greece, shows a typical exhumed detachment of Late Oligocene-Early Miocene age (Avigad and Garfunkel 1989; Gautier and Brun 1994b) which is now discussed to illustrate the stratification of the deformation mode advocated above. Early Miocene greenschist facies retrogression was accompanied by an intense deformation characterized by a top-to-the-north-east shear, which is preferentially localized within a NE-dipping shear zone in the north of the island. This exhumed detachment fault separates the retrograded blueschist facies unit from an upper unit devoid of high-pressure parageneses (Gautier and Brun 1994a; Patriat and Jolivet 1998; Jolivet and Patriat 1999). A similar pattern of deformation has been active in the region of the Gulf of Corinth, from the Early Miocene to the present, with extension controlled by north or north-east-dipping shear zones (Le Pichon et al. 1994; Armijo et al. 1996). Therefore, it is believed that the exhumed detachment fault, observable at the surface in the northern part of Tinos, corresponds to the same structure studied below the Gulf of Corinth at a depth close to $10 \mathrm{~km}$. Then, the description of the time evolution of the deformation regimes on Tinos, during progressive unroofing of HP-LT rocks, informs us of the stratification of the crust in term of deformation modes. Coaxial stretching is the dominant mode of deformation for greenschist facies rocks in the south of the island, whereas in the north an increase in shear strain is marked by the formation of shear bands below the detachment, suggestive of simple shear deformation. The detachment zone, characterized by a progressive evolution from ductile to brittle behaviour, the presence of fluids and a decrease in the grain size (mylonitization), corresponds to the brittle stage of the strain localization process within the ductile lower crust (Patriat and Jolivet 1998).

In conclusion, the stratification proposed by Jolivet and Patriat (1999) is adopted: normal faulting in the upper crust, shear bands at the brittle-ductile transition (inducing microseismicity) and coaxial stretching in the deeper lower crust (Fig. 1).

\section{Model of the continental crust in extension}

The above discussion on the structure of metamorphic core complexes justifies the introduction of the model of an extending continental crust presented in Fig. 1. The presence in the upper crust of conjugate normal faults provides, with the formation of a graben, a 


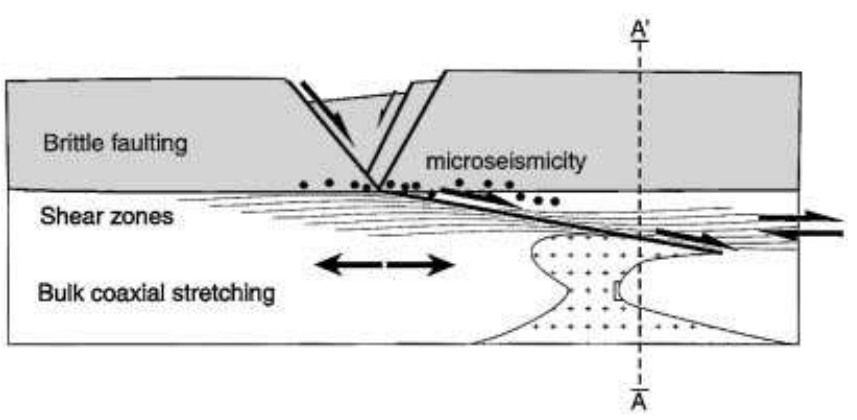

Fig. 1 Structural model of the continental crust in extension

mechanism for an easy extension of the upper crust. The upper crustal material away from these normal faults is then not deforming and is assumed to glide rigidly over the lower crust. Therefore, at a large distance from the graben, as in section $\mathrm{AA}^{\prime}$ of Fig. 1, the kinematics is a simple shear of the lower crust induced by the rigid gliding of the upper crust. Our model problem consists then of two layers of infinite horizontal extent, defined by the upper and lower crust. The top layer does not deform; it conducts heat and applies to the lower crust a velocity which varies suddenly with time due to the formation of the graben (Fig. 2). The objective of this study is to analyse the increase in the magnitude of the shear stress in the lower crust in response to the change in the upper crust velocity with time.

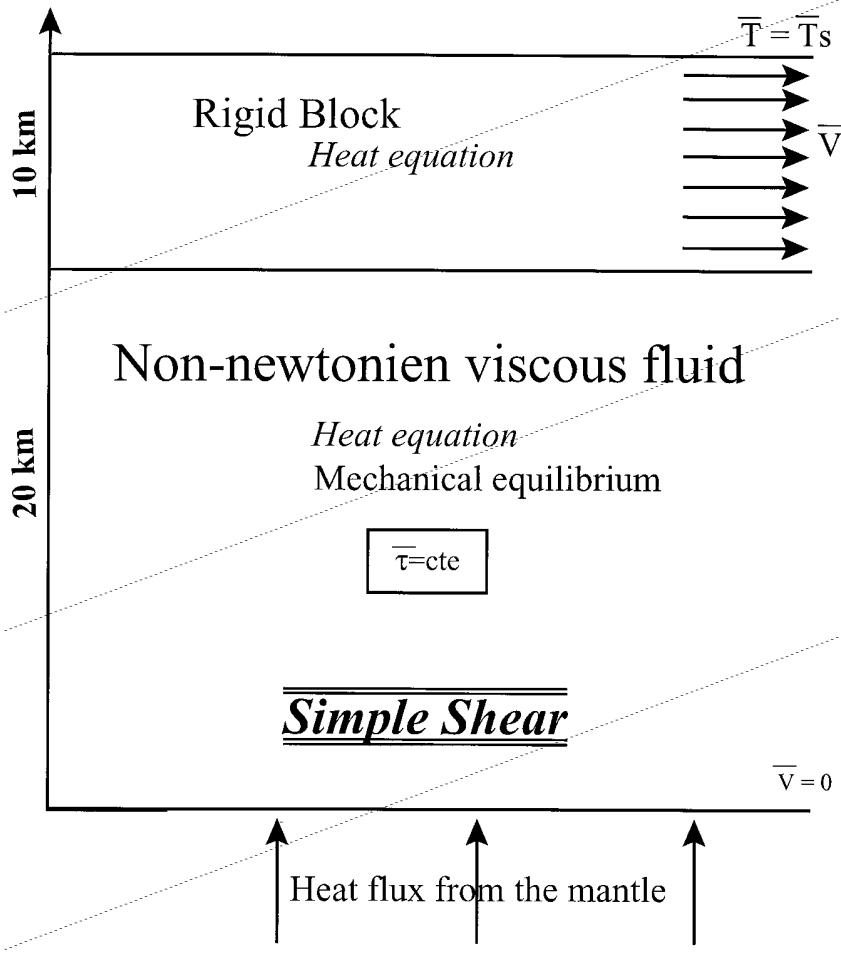

Fig. 2 1-D structural model motivated by section $\mathrm{AA}^{\prime}$ of Fig. 1

\section{The model problem}

This section starts with a description of the layered structure proposed for studying the shear stress enhancement at the brittle-ductile transition. The second part deals with the constitutive relations adopted for the material in the lower crust. The third part is devoted to dimensional analysis prior to the presentation of the numerical results in the next section.

\section{The layered structure}

The two layers which compose our structural model are the upper crust and the lower crust, both of infinite lateral extent and of thickness $l_{\mathrm{u}}(10 \mathrm{~km})$ and $l_{1}$ $(20 \mathrm{~km})$, respectively (Fig. 2). This simple model was referred to in the previous section and corresponds to section $\mathrm{AA}^{\prime}$ in Fig. 1. The rigid translation of the upper crust has to be kinematically compatible with the lower crust, which is then assumed to sustain an overall simple shear mode of deformation. The stretching of the lower crust, which should be superposed on the shear mode of deformation, is assumed to take place at a much lower rate than the rate of translation of the upper crust and is disregarded in this analysis.

The mechanical equilibrium in the lower crust, for this Couette shear flow, reads

$\frac{\partial \bar{\tau}}{\partial \bar{y}}=0$

where $\bar{\tau}$ and $\bar{y}$ are the shear stress and the vertical coordinate, with origin at the Moho, respectively. The magnitude of the shear stress $\bar{\tau}$, constant over the whole domain according to Eq. (1), is what we wish to determine in this study. Note that in Eq. (1) as well as in the rest of this paper a superposed bar indicates that the variable or the scalar highlighted has a physical dimension. For the mechanical boundary condition, the observer is positioned at the interface with the lithospheric mantle, justifying our choice of a zero velocity at that depth $(\overline{\mathrm{v}}(\bar{y}=0)=0)$. All velocities discussed in what follows should thus be understood as relative to the lithospheric mantle. At the upper crust contact, the velocity $\overline{\mathrm{V}}$ is prescribed and varies with time.

The temperature distribution over the whole crust is governed by the heat equation:

$\bar{\rho}_{\alpha} \bar{C} \dot{\bar{T}}-\bar{k}_{\alpha} \frac{\partial^{2} \bar{T}}{\partial \bar{y}^{2}}=\bar{r}_{\alpha}+\bar{\tau} \dot{\bar{\gamma}}$,

in which $\bar{T}, \dot{\bar{\gamma}}, \bar{\rho}_{\alpha}, \bar{C}, \bar{k}_{\alpha}$ and $\bar{r}_{\alpha}$ are the temperature, the shear strain rate, the material density, the heat capacity, the conductivity and the radiogenic heat production rate, respectively, in either the lower $(\alpha=l)$ or the upper crust $(\alpha=u)$. A superposed dot in Eq. (2) stands 
for the partial differentiation with respect to time so that $\dot{\bar{\gamma}}$ is understood as the spatial gradient of the velocity field $\bar{v}(\bar{y}): \dot{\bar{\gamma}}=\partial \overline{\mathrm{v}} / \partial \bar{y}$. The second term in the right-hand side of Eq. (2) is the amount of work due to deformation converted into heat. This shear heating vanishes in the upper crust since the rigid body translation there leads to a zero strain rate. The known heat flux forms the lithospheric mantle $\bar{q}_{l}$ and the fixed temperature of the surface, $\bar{T}_{s}$, provide the necessary boundary conditions to solve Eq. (2)

\section{Constitutive relations for the lower crust}

We now turn our attention to the rheological model adopted for the continental crust material. Since the upper crust is considered to be rigid, the rheology has to be defined in the lower crust only. At the depth of interest (between 10 and $30 \mathrm{~km}$ ) two micro-mechanisms of deformation are potentially concurrently activated in a given representative elementary volume (REV), namely, dislocation creep and diffusion creep. Note that only the irreversible part of the deformation is accounted for and the elastic deformation is thus disregarded.

Dislocation creep is an intracrystalline deformation mechanism resulting in a temperature and strain-rate dependent creep law

$\frac{\dot{\bar{\gamma}}_{r}}{\overline{\bar{\gamma}}_{o r}}=\exp \left[-\beta_{r}\left(\frac{\bar{T}_{o}}{\bar{T}}-1\right)\right]\left(\frac{\bar{\tau}}{\bar{\tau}_{o r}}\right)^{n}$

where $\dot{\bar{\gamma}}_{r}$ is the strain rate for dislocation creep over the REV. The scalars $\dot{\bar{\gamma}}_{o r}, \beta_{r}, \bar{T}_{o}$ and $\bar{\tau}_{o r}$ in Eq. (3) are the characteristic strain rate for dislocation creep, the Arrhenius constant, the characteristic temperature for the lower crust, and the characteristic shear stress for dislocation creep, respectively.

The second deformation mechanism activated in the REV is diffusion creep, which is an intercrystalline deformation mechanism. It is temperature and strainrate dependent but also grain-size sensitive, resulting in the following rheological law:

$\frac{\dot{\bar{\gamma}}_{d}}{\dot{\bar{\gamma}}_{o d}}=\exp \left[-\beta_{d}\left(\frac{\bar{T}_{o}}{\bar{T}}-1\right)\right] \frac{\bar{\tau}}{\bar{\tau}_{o d}}\left(\frac{\bar{d}}{\bar{d}_{o}(\bar{T})}\right)^{-p}$

where the variables introduced have the same definitions as the ones provided after Eq. (3). The only difference between Eqs. (4) and (3), apart from the grain-size sensitivity, is that the subscript $d$ stands for diffusion creep and replaces the subscript $r$ found in Eq. (3) and attached to the recovery or dislocation creep mechanism. In Eq. (4), the scalar $\bar{d}_{o}(\bar{T})$ introduced remains to be defined and is the characteristic grain size. This scalar is a function of temperature to account for static grain growth or annealing, which occurs in time and in the absence of any deformation. Disregarding the time dependency of annealing com- pared to the characteristic time of our problem (defined in 'Dimensional analysis' and taking the value $14 \mathrm{My}$ ), we assume that the time-independent value of $\bar{d}_{o}$ is controlled only by temperature and is approximated in the lower crust by the relation

$\bar{d}_{o}(\bar{T})=\bar{d}_{s} \exp \left(\bar{k}\left(\frac{\bar{T}-\bar{T}_{o}}{\bar{T}_{o}}\right)\right)$

where $\bar{d}_{s}$ and $\bar{k}$ are the characteristic grain size at $\bar{T}_{o}$ and the activation energy for annealing, respectively. The scalar $\bar{d}_{s}$ is estimated in 'Dimensional analysis'. It appears that there is no constraint from laboratory findings on the activation energy $\bar{k}$. However, there is general agreement on the evolution of the characteristic grain size within the lower crust: the grain-size of greenschist rocks (brittle-ductile transition) is smaller than the grain-size for granulite (Moho conditions). To account for this geological evidence, the activation energy for annealing is set to $\bar{k}=10$, leading to a reasonable variation in grain size by a factor of 10 between the upper part and lower part of the lower crust, as will be seen in 'Numerical results'.

Having defined the two deformation mechanisms active in the REV, we turn our attention to their contribution to the total deformation rate. For a given mineral, quartz or anorthite, it is assumed that the same shear stress controls the two deformation mechanisms. Therefore, dislocation creep and diffusion creep are activated in series and the total strain rate $\dot{\bar{\gamma}}$ is the sum of the strain rate due to dislocation creep $\dot{\bar{\gamma}}_{r}$ and the strain rate due to diffusion creep $\dot{\bar{\gamma}}_{d}$ :

$\dot{\bar{\gamma}}=\dot{\bar{\gamma}}_{r}+\dot{\bar{\gamma}}_{d}$

The rest of this subsection is devoted to the grainsize evolution law and steady state values. The key issue is the definition of the steady-state grain size, also called the mean grain size in the literature, which acts as an attractor during transient evolutions. This steady-state value is not the value deduced from piezometric measurements and adopted by Kameyama et al. (1997) and Braun et al. (1999). In that case, the recrystallized grain size-stress relationship is independent of the boundary between dislocation creep and diffusion creep domains in a deformation map (Derby and Ashby 1987; Shimizu 1998). Handy (1989) showed that the transition from dislocation creep to diffusion creep fields occurs without a grain-size evolution towards the equilibrium values. Jin and Karato (1998) demonstrated further that for crustal conditions the differences between the piezometric values and the transient grain size leads to major rheological weakening. However, dynamic recrystallization of crustal material seems to correspond to a balance between grain-size reduction and grain growth occurring at the boundary between dislocation and diffusion creep domains (Derby and Ashby 1987). This hypothesis led de Bresser et al. (1998) to propose that the steadystate mean grain size represents a balance between 
grain-size sensitive and grain-size insensitive flow. Steady-state conditions on the boundary between the two domains require the two deformation rates to be identical:

$\dot{\bar{\gamma}}_{r}=\dot{\bar{\gamma}}_{d}$

The mean grain size, denoted $\bar{D}$, is then determined by combining Eqs. (3) and (4) and reads

$\bar{D}(\bar{\tau}, \bar{T})=\bar{D}_{o}(\bar{T}) \exp \left[\frac{\beta_{r}-\beta_{d}}{p}\left(\frac{\bar{T}_{o}}{\bar{T}}-1\right)\right]\left(\frac{\bar{\tau}}{\bar{\tau}_{o r}}\right)^{\frac{1-n}{p}}$,

with

$$
\bar{D}_{o}(\bar{T}) \equiv \bar{d}_{o}(\bar{T})\left(\frac{\bar{\tau}_{o r} \dot{\bar{\gamma}}_{o d}}{\bar{\tau}_{o d} \dot{\bar{\gamma}}_{o r}}\right)^{\frac{1}{p}}
$$

A justification of the model advocated by de Bresser et al. (1998) can be gained from analysis of the deformation map, for example of quartz (Fig. 3). Four curves are presented defining the stress as a function of grain size at a constant strain rate. The definition of the steady-state grain size (Eq. 8) with the steady-state condition (Eq. 7) implies that the representative curve for $\bar{D}$ in Fig. 3 corresponds to the transition between the dislocation creep and diffusion creep regimes. This transition zone contains within the limits of experimental error the piezometric lines based on the measurements of Twiss (1977), Mercier et al. (1977) and Christie et al. (1980). These measurements were conducted for conditions close to steady states and justify the assumption made by de Bresser et al. (1998).

The evolution of the grain size $\bar{d}(\bar{t})$ now needs to be described to complement our rheological model.
We propose here that the steady-state value of the grain size, $\bar{D}$, acts as an attractor and that the grain size evolves according to

$\dot{\bar{d}}_{\alpha}=-a_{\alpha} \dot{\bar{\gamma}}_{\alpha}(\bar{d}-\bar{D}) \quad(\alpha=r, d)$.

The rate of change of the grain size due to either mechanism has its sign determined by the difference between the current value of the grain size and the attractor value. The magnitude of this rate is determined by this difference multiplied by the amount of strain rate and a scalar denoted $a_{\alpha}$. Note that the evolution ceases if either the steady state is reached $(\bar{d}=\bar{D})$ or the deformation mechanism is not activated. Other evolution laws for grain size are found in the literature, especially for olivine (Derby and Ashby 1987; Kameyama et al. 1997; Braun et al. 1999). Equation (9) is simpler than the ones referred above in the sense that it combines the evolution law for grain-size reduction and grain growth in a single expression. Laboratory results are lacking that would justify the introduction of further complexity in the evolution law for lower-crustal material. Equation (9) predicts grain-size evolution as follows: in the dislocation creep regime $(\alpha=r)$, the current grain size is larger than the steady-state grain size $(\bar{d} \geq \bar{D})$, leading to grain-size reduction. In diffusion creep field $(\alpha=d)$, the grain size is smaller than the equilibrium grain size $(\bar{d} \leq \bar{D})$, inducing grain growth (see Fig. 3).

It is further assumed that dislocation creep and diffusion creep occur concurrently, modifying the grain size, which rate of evolution is therefore defined by the sum:
Fig. 3 Deformation mechanism map at $\bar{T}=800 \mathrm{~K}$ for quartz and a coupling in series of dislocation creep and diffusion creep. The shear stress is regarded as a function of grain size and strain rate. The solid curves are computed with a constant strain rate. The dashed curves correspond to the piezometric relation between the shear stress and the grain size found in the literature (Mercier et al. 1977; Twiss 1977; Christie et al. 1980). The rheological data used to construct this map are presented in Table 2

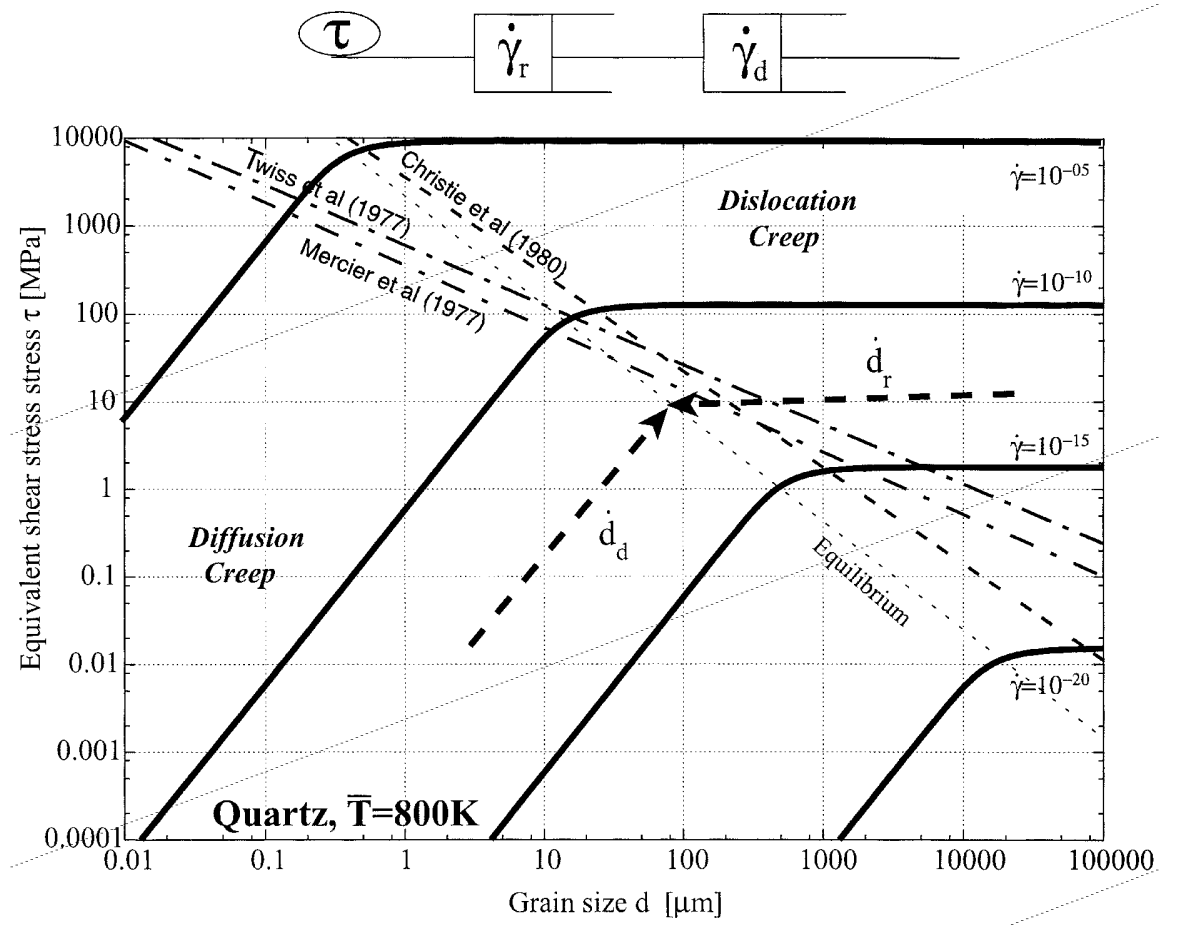


$\dot{\bar{d}} \equiv \dot{\bar{d}}_{r}+\dot{\bar{d}}_{d}=-\left[a_{r} \dot{\bar{\gamma}}_{r}+a_{d} \dot{\bar{\gamma}}_{d}(\bar{d}-\bar{D})\right.$

The complete rheological model is summarized by Eqs. (3) to (10) and is thus temperature, strain-rate and grain-size dependent. Grain-size reduction and growth during transient evolution and static annealing are accounted for. We now turn our attention to the scaling of the governing equations and the constitutive relations.

Before doing so, it should be stressed that the steady-state conditions defining the grain size attractor $\bar{D}$ are not the same as the steady-state conditions for the shear flow over the whole crust controlled by conduction. This difference is important for understanding the evolution in time of the grain-size distribution through the lower crust discussed in 'Numerical results'.

\section{Dimensional analysis}

Any physical variable $\bar{a}$ will be associated to the dimensionless variable $a$, multiplied by its reference value. For example, dimensionless length, temperature, shear stress, time, strain rate and grain size are defined by

$y=\frac{\bar{y}}{\bar{l}_{l}}, T=\frac{\bar{T}}{T_{o}}, \tau=\frac{\bar{\tau}}{\bar{\tau}_{o}}, t=\frac{\bar{t}}{\bar{t}_{c}}, \dot{\gamma}=\frac{\dot{\bar{\gamma}}}{\bar{\gamma}_{o}}, d=\frac{\bar{d}}{\bar{d}_{o}(T)}$

in which $\bar{t}_{c}, \bar{T}_{0}, \bar{\tau}_{0}, \dot{\bar{\gamma}}_{0}$ and $\bar{d}_{o}(T)$ are the characteristic time of conduction in the lower crust $\left(\bar{t}_{c}=\bar{\rho}_{l} \bar{C} \bar{l}_{l}^{2} / \bar{k}_{l}\right)$, the average temperature of the lower crust (set to $\bar{T}_{0}=800 \mathrm{~K}$ ), the characteristic shear stress (see below for its value), the characteristic strain rate (defined by $\dot{\bar{\gamma}}_{0}=1 / \bar{t}_{c}$ ) and the characteristic grain size (defined by Eq. (5) and estimated below), respectively. Dimensionless variables or constants are thus always without a superposed bar. The data required to define the characteristic values are now discussed.

Experimental data for the flow laws in the lower crust

The most common minerals in the lower crust are quartz and feldspar. Among all feldspars, anorthite has received the most attention in the literature and is selected here. Experimental data for dislocation creep, either for quartz and anorthite, are often presented in the form:

$\dot{\bar{\gamma}}_{r}=\bar{A} \exp \left[-\frac{\bar{Q}_{r}}{\bar{R} \bar{T}}\right] \bar{\tau}^{n}$

where $\bar{Q}_{r}, n$ and $\bar{A}$ are the activation energy for dislocation creep, the stress exponent, and a pre-exponential constant, respectively. Comparison of Eq. (12) with Eq. (3) provides the link between the constants $\bar{A}, \bar{Q}_{r}$ and $n$ with the constant used in our rheological model:
$\beta_{r}=\frac{\bar{Q}_{r}}{R T_{o}} \quad$ and $\quad \bar{\tau}_{o r}=\left[\frac{\dot{\bar{\gamma}}_{o r} \exp \left(\beta_{r}\right)}{A}\right]^{\frac{1}{n}}$.

The characteristic strain rate for dislocation creep, $\dot{\bar{\gamma}}_{o r}$, is set to the characteristic strain rate of our problem $\dot{\bar{\gamma}}_{o}$. The values of the constants introduced in Eq. (13) are determined from the experimental flow law for dislocation creep found in Koch et al. (1989) for quartz and in Shelton (1981) for anorthite and are presented in Table 2 .

For diffusion creep, few experimental data are available for lower crustal rocks, except for the data at high temperature for anorthite (Wang et al. 1996). In the absence of any constraint from laboratory experiments, the activation energy for diffusion creep $\bar{Q}_{d}$ is assumed to be proportional to the activation energy for dislocation creep $\bar{Q}_{r}$. Putting $\bar{Q}_{d} \approx 0.6 \bar{Q}_{r}$ (Frost and Ashby 1982; Evans and Kohlstedt 1995) permits us to define the dimensionless Arrhenius constant for diffusion creep:

$\beta_{d}=\frac{\bar{Q}_{d}}{\bar{R} \bar{T}_{o}} \approx 0.6 \beta_{r}$.

The most common steady-state grain-size relation to stress and temperature (Derby and Ashby 1987; de Bresser et al. 1998) has the following form:

$\bar{D}=\bar{K} \exp \left[\frac{\bar{Q}_{r}-\bar{Q}_{d}}{p \bar{R} \bar{T}}\right] \bar{\tau}^{\frac{1-n}{p}}$

where $p$ and $\bar{K}$ are the grain size exponent and a preexponential constant. Comparison of Eq. (15) with Eq. (8) provides the characteristic grain size at the reference temperature $\bar{T}_{0}$, missing so far from our model:

$\bar{d}_{s}=\bar{K}\left(\bar{\tau}_{o d}\right)^{\frac{1-n}{p}} \exp \left(\frac{\beta_{r}-\beta_{d}}{p}\right)$

The characteristic shear stress for diffusion creep $\bar{\tau}_{\text {od }}$ is set to the characteristic shear stress for dislocation creep $\bar{\tau}_{o r}$ and the characteristic strain rate for dislocation creep $\dot{\bar{\gamma}}_{o d}$ to $\dot{\bar{\gamma}}_{o}$. In the absence of any other data, the value of the pre-exponential constant $\bar{K}$ is set to the one found for a crustal rock analogue Magnox (Drury et al. 1985; de Bresser et al. 1998). Changing this value results in a scaling of the exact grain size but does not change the rest of the results.

Finally, the characteristic shear stress and grain size for our 1-D problem is selected as the minimum value of $\bar{\tau}_{o r}$ and $\bar{d}_{s}$, found for quartz and anorthite. These scalars are given in Table 1 . The dimensionless values are summarized in Table 2.

\section{Dimensionless governing equations}

We are now in a position to rewrite the governing Eqs. (1) to (10) with a set of dimensionless variables. The equilibrium Eq. (1) stipulates that a constant shear stress $\tau$ prevails over the whole lower crust. 
Table 1 Reference values for physical parameters and dimensionless numbers used in our numerical computation

\begin{tabular}{llcl}
\hline Physical quantity & Definition & Values & Unit \\
\hline Characteristic values & & & \\
$\bar{l}_{l}$ & Reference length & 20 & $\mathrm{~km}$ \\
$\overline{\bar{\gamma}}_{o}$ & Reference strain rate & $2.210^{-15}$ & $\mathrm{~s}^{-1}$ \\
$\bar{t}_{c}$ & Reference time: conduct time in lower crust & 14 & $\mathrm{My}$ \\
$\bar{t}_{c}$ & Reference shear stress & 2.4 & $\mathrm{MPa}$ \\
$\bar{d}_{s}$ & Reference grain size & 265 & $\mu \mathrm{m}$ \\
$\bar{T}_{o}$ & Reference temperature & 800 & $\mathrm{~K}$ \\
Model parameters & & & \\
$\bar{l}_{l}$ & Lower crust thickness & 20 & $\mathrm{~km}$ \\
$\bar{l}_{u}$ & Upper crust thickness & 10 & $\mathrm{~km}$ \\
$\bar{\rho}_{u}$ & Upper crust destiny & 2650 & $\mathrm{Kg} / \mathrm{m}^{3}$ \\
$\bar{\rho}_{l}$ & Lower crust destiny & 2800 & $\mathrm{~kg} / \mathrm{m}^{3}$ \\
$\bar{q}_{l}$ & Heat flux from the mantle & 30 & $\mathrm{~mW} / \mathrm{m}^{2}$ \\
$\bar{r}_{u}$ & Radiogenic heat production (upper crust) & 1.5 & $\mu \mathrm{W} / \mathrm{m}^{3}$ \\
$\bar{r}_{l}$ & Radiogenic heat production (lower crust) & 0.2 & $\mu \mathrm{W} / \mathrm{m}^{3}$ \\
$\bar{k}_{u}$ & Heat conductivity (upper crust) & 2.1 & $\mathrm{~W} / \mathrm{m} \mathrm{K}^{3}$ \\
$\bar{k}_{l}$ & Heat conductivity (lower crust) & 2.5 & $\mathrm{~W} / \mathrm{m} \mathrm{K}^{\mathrm{K}}$ \\
$\bar{C}$ & Heat capacity & 1000 & $\mathrm{~J} /(\mathrm{kg} \mathrm{K})$ \\
Dimensionless numbers & & \\
$\xi_{\mathrm{u}}$ & Heat capacity (upper crust) & 1.12 & \\
$\zeta_{1}$ & Heat capacity (lower crust) & 1.0 & \\
$\lambda_{\mathrm{u}}$ & Shear heating (upper crust) & 0.0 & \\
$\lambda_{1}$ & Shear heating (lower crust) & 0.004 & \\
\hline & & & \\
\hline
\end{tabular}

Table 2 Material properties for quartz and anorthite, for dislocation creep and diffusion creep deformation mechanisms. For dislocation creep, data are from Koch et al. (1989) for quartz and Shelton (1981) for anorthite. For diffusion creep, the parameters are computed using Eqs. (14) and (16) and the steady-state grain size distribution $(\mathrm{Eq}, 15)$ for the rock analogue Magnox (de Bresser et al. 1998)

\begin{tabular}{|c|c|c|c|}
\hline & Definition & Quartz & Anorthite \\
\hline \multicolumn{4}{|c|}{ Dislocation creep flow parameters } \\
\hline$\beta_{\mathrm{r}}$ & Arrhenius constant & 20.1 & 35.8 \\
\hline $\mathrm{n}$ & Stress exponent & 2.7 & 3.2 \\
\hline$\dot{\gamma}_{\text {or }}$ & Characteristic strain rate & 1 & 1 \\
\hline$\tau_{\text {or }}$ & Characteristic shear stress & 1 & 9.6 \\
\hline \multicolumn{4}{|c|}{ Diffusion creep flow parameters } \\
\hline$\beta_{\mathrm{d}}$ & Arrhenius constant & 12.1 & 21.5 \\
\hline $\mathrm{p}$ & Grain size exponent & 2 & 2 \\
\hline$\dot{\gamma}_{\text {od }}$ & Characteristic strain rate & 1 & 1 \\
\hline$\tau_{\rho}$ & Characteristic shear stress & 1 & 9.6 \\
\hline $\mathrm{d}_{\mathrm{s}}$ & Characteristic grain size & 1 & 1.5 \\
\hline $\mathrm{k}$ & Annealing temperature activation & 10 & 10 \\
\hline$a_{r}$ & Rate of grain size reduction & 1 & 1 \\
\hline$a_{d}$ & Rate of grain growth & 1 & 1 \\
\hline
\end{tabular}

The heat equation for the whole crust now takes the form:

$$
\xi_{\alpha} \dot{T}-\frac{\partial^{2} T}{\partial y^{2}}=r_{\alpha}+\lambda_{\alpha} \tau \dot{\gamma} \quad(\alpha=u, l),
$$

in which, again, the subscript $\alpha$ is either $u$ or $l$ for the upper and lower crust, respectively. The dimensionless numbers introduced in Eq. (17) are, for the upper crust:

$$
\xi_{u}=\frac{\bar{\rho}_{u} \bar{k}_{l}}{\bar{\rho}_{l} \bar{k}_{u}}, \quad r_{u}=\frac{\bar{r}_{u} \bar{l}_{l}^{2}}{\bar{k}_{u} \bar{T}_{0}}, \quad \lambda_{u}=0,
$$

and are referred to as the dimensionless capacity, the radiogenic heat production and the shear heating coefficient, respectively. In the upper crust, Eq. (17) reduces to the classical heat diffusion equation with no coupling to the mechanical part of the problem $\left(\lambda_{u}=0\right)$.

For the lower crust, the dimensionless numbers introduced in Eq. (17) are:

$$
\xi_{l}=1, \quad r_{l}=\frac{\bar{r}_{l} l_{l}^{2}}{k_{l} \bar{T}_{o}}, \quad \lambda_{l}=\frac{\bar{\tau}_{o}}{\bar{\rho}_{l} \bar{C} \bar{T}_{o}} .
$$

The values of these dimensionless numbers are given in Table 1 and were estimated from the data found in Turcotte and Schubert (1982).

The complete dimensionless rheological model for the lower crust is now summarized by the set of equations:

$$
\begin{aligned}
& \dot{\gamma}=\dot{\gamma}_{r}+\dot{\gamma}_{d} \\
& \dot{\gamma}_{r}=\dot{\gamma}_{o r} \exp \left[-\beta_{r}\left(\frac{1}{T}-1\right)\right]\left(\frac{\tau}{\tau_{o r}}\right)^{n} \\
& \dot{\gamma}_{d}=\dot{\gamma}_{o d} \exp \left[-\beta_{d}\left(\frac{1}{T}-1\right)\right] \frac{\tau}{\tau_{o d}}\left(\frac{d}{d_{o}(T)}\right)^{-p}, \\
& \dot{d}=-\left[a_{r} \dot{\gamma}_{r}+a_{d} \dot{\gamma}_{d}\right](d-D)
\end{aligned}
$$


Note again that in steady-state conditions there is no grain-size evolution and the variation of the grain size with depth is defined by the equilibrium condition $\dot{\gamma}_{r}=\dot{\gamma}_{d}$ and reads

$$
\begin{aligned}
d= & D=d_{s} \exp (k(T-1))\left(\frac{\tau_{o r} \dot{\gamma}_{o d}}{\tau_{o d} \dot{\gamma}_{o r}}\right)^{\frac{1}{p}} \\
& \exp \left(\frac{\beta_{r}-\beta_{d}}{p}\left(\frac{1}{T}-1\right)\right)\left(\frac{\tau}{\tau_{o r}}\right)^{\frac{1-n}{p}} .
\end{aligned}
$$

The governing equations are completed by the mechanical and thermal boundary conditions, which read

$$
\begin{array}{lc}
\frac{\partial T}{\partial y}{ }_{\mid y=0}=-q_{l}, & T(y=l)=T_{s}, \\
\mathrm{v}(y=0)=0 \quad \text { and } \quad & \mathrm{v}(y=l)=V,
\end{array}
$$

where $V$ is the imposed velocity of the upper crust.

\section{Numerical results}

The numerical calculations presented in this section are intended to quantify the increase in equivalent shear stress from the steady-state values during a rapid change in extension rate of the upper crust. Steady-state solutions are first presented. As discussed earlier in this paper (see 'Constitutive relations for the lower crust'), they correspond to an equilibrium between the dislocation creep and diffusion creep deformation mechanism (Eq. 7) and are thus fully defined by the dislocation creep flow law (Eq. 21) which is only strain-rate and temperature dependent. The grain-size sensitivity comes into play only during transient evolution, which will be presented in the second part of this section.

Before proceeding, a word on the numerical method employed, discussed in detail in Gueydan (2001), is in order. The discretization of space is based on the finite-element method and the discretization in time on a finite-difference scheme. The whole crust is partitioned into 150 elements (50 for the upper crust and 100 for the lower crust) and the representative elementary length is thus of the order of $200 \mathrm{~m}$.

\section{Steady states in the lower crust}

A typical steady-state velocity profile through the whole crust is plotted in Fig. 4a. This velocity is constant in the upper crust, assumed to be rigid, and varies linearly in the lower crust if a Newtonian rheology is considered for anorthite. However, adoption of the temperature and strain-rate sensitive rheology described in the previous section leads to a rather constant velocity in the upper part of the lower crust and a rapid variation to zero as the Moho is approached. This zero value marks the fact that the observer is attached to the Moho (see boundary conditions in
Eq. 25). The velocity profile implies a tendency for shear localization at the Moho transition which is more pronounced for anorthite than for quartz. This trend is due to the lower activation energy for quartz than for anorthite (see values of Arrhenius constants for dislocation creep law in Table 2). This tendency for the deformation to localize at the Moho contact is now further justified by the analysis of the temperature profile through the whole crust presented in Fig. 4b.

The temperature varies approximately linearly with depth in the lower crust as a result of conduction, with a small contribution to the heat flux of the mechanical work converted into heat and of the radiogenic source (see Eq. 17 and Table 1 for the corresponding values of dimensionless numbers for the lower crust). The two temperature profiles obtained for the non-linear rheologies reveal a larger temperature for anorthite than for quartz. This difference must be due to the larger amount of shear heating [term $\tau \dot{\gamma}$ of Eq. 17)] for anorthite. A first explanation would be to invoke the larger strain rate $\dot{\gamma}$ close to the Moho for this mineral (Fig. 4a). However, the highest temperature is obtained for the linear velocity profile and thus occurs in the absence of any trend towards localization. Therefore, the difference in temperature at the Moho must be explained by a difference in shear stress $\tau$ for the three rheologies discussed. Indeed, an inspection of Fig. 5, which presents the steady-state solutions in terms of stress versus velocity at the contact of the upper crust, reveals that for the velocity of 5 selected for drawing Fig. 4a the shear stress is 3.5 and 7 times greater for anorthite and for the linear rheology than for quartz.

The final observation on Fig. $4 \mathrm{~b}$ is that the temperature is twice as high, approximately, at the Moho as at the contact with the upper crust. This difference in temperature implies there is a greater apparent viscosity close to the upper crust and explains the tendency for the deformation to localize at the Moho, seen in Fig. 4a for temperature-dependent rheologies.

The steady-state grain-size distribution through the lower crust is presented in Fig. 4c using Eq. (24) and the stationary velocity and temperature profiles of Fig. 4a, b. This distribution is plotted for quartz and anorthite, accounting or not for static annealing. The large strain rate at the contact of the Moho is responsible for a grain-size reduction in that region compared to the upper part of the lower crust. Such a distribution, obtained in the absence of annealing, is not in line with field evidence. Therefore, the static graingrowth law described by Eq. (5) as a function of temperature is accounted for in the rest of this section: the grain size increases with depth, as seen in Fig. 4c. Note that the grain size with static annealing for anorthite is then twice as large as for quartz at the Moho contact. This is partly due to the characteristic grain size $d s$, provided in Table 2 , which enters Eq. (24). Another reason is the larger difference in the Arrhe- 

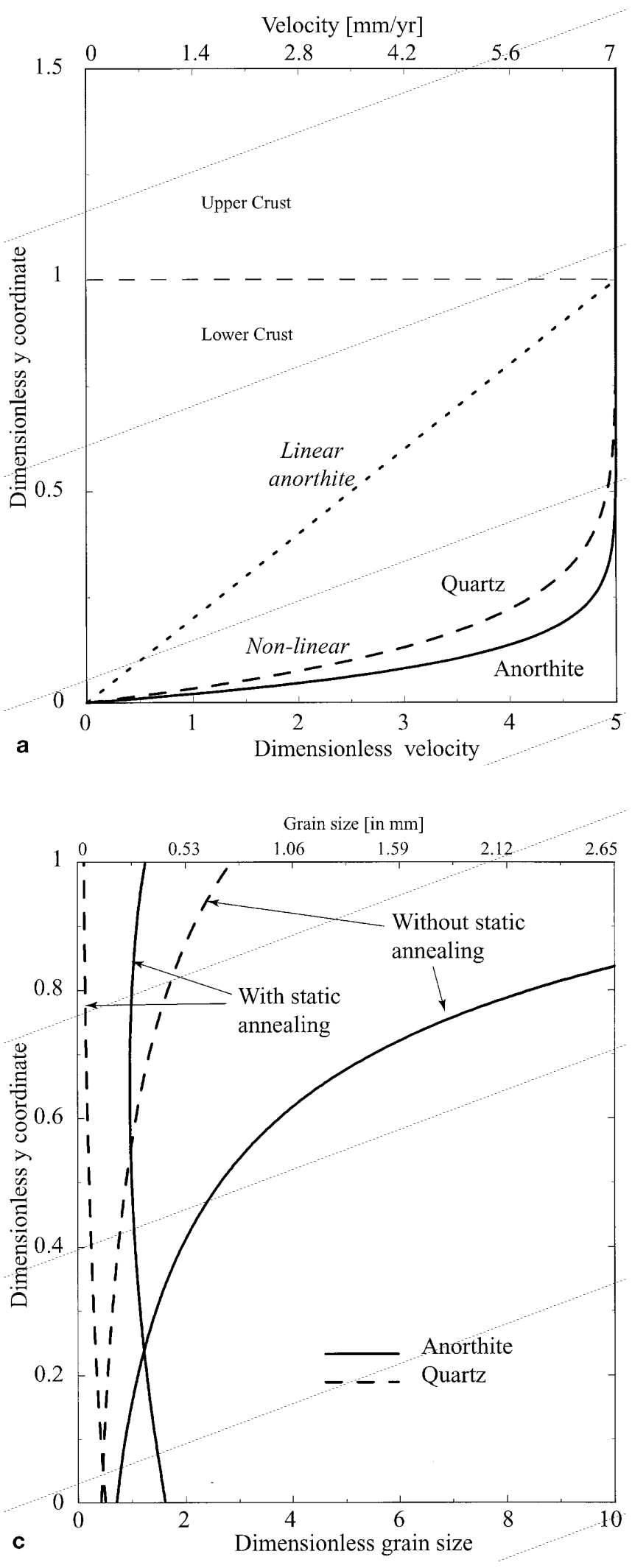

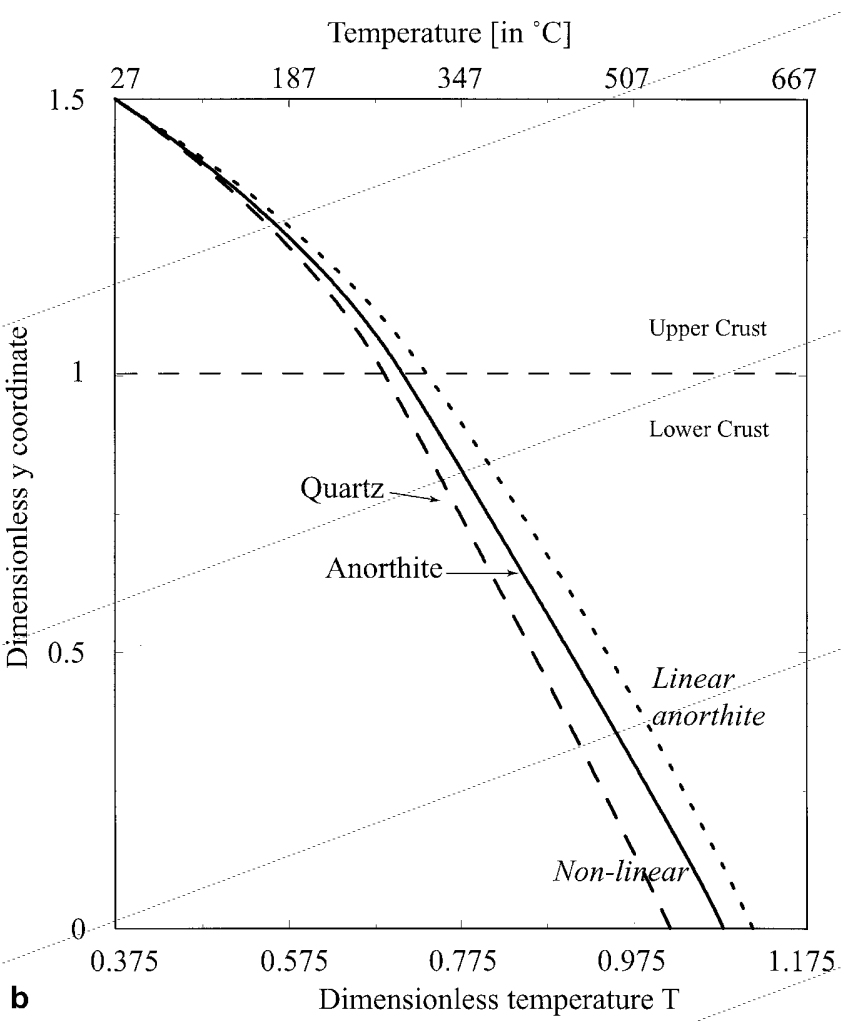

Fig. 4 Steady-state velocity (a), temperature (b) and grain size (c) profiles. Note that the top and the bottom of the diagrams correspond to the surface and to the Moho, respectively. The coordinate $y=1.0$ corresponds to the contact between the upper and lower crust. In a and $\mathbf{b}$, the velocity and temperature profiles for quartz are the dashed curve, for anorthite the solid curve and for a linear rheology the dotted line. In c, the grain size distribution in the lower crust is compared with and without static grain growth for quartz (dashed curve) and anorthite (solid curve)

nius constants for anorthite than for quartz (Table 2 and Eq. 24, again). This difference also explains why the stationary grain size increases slightly in the region close to the upper crust for anorthite.

The comparison between the two non-linear rheologies is continued with the analysis of the stress-velocity relations in Fig. 5. For every velocity prescribed at the upper crust contact there is a unique value of the shear stress, which is constant over the whole lower crust to enforce mechanical equilibrium (Eq. 1). To the contrary, for a given value of the shear stress there are 2, 1 or 0 possible values of the gliding velocity of the upper crust, depending on the magnitude of the shear stress (Fig. 5). The stress is a multi-valued function of the velocity because of the presence of a maximum in stress $\tau \max$, associated to a critical velocity $V$ c, which partitions the steady-state curve into two parts: the subcritical branch and the supercritical branch. The increasing section of the stress-velocity curve prior to the critical velocity is dominated by the strain-rate sensitivity of the constitutive law and the 
Fig. 5 Dimensionless equivalent shear stress as a function of the dimensionless velocity at the contact of the upper crust for steady state flow in the lower crust. Three materials are considered: anorthite (solid curve), quartz (dashed curve) and a linear viscous material (dotted curve)

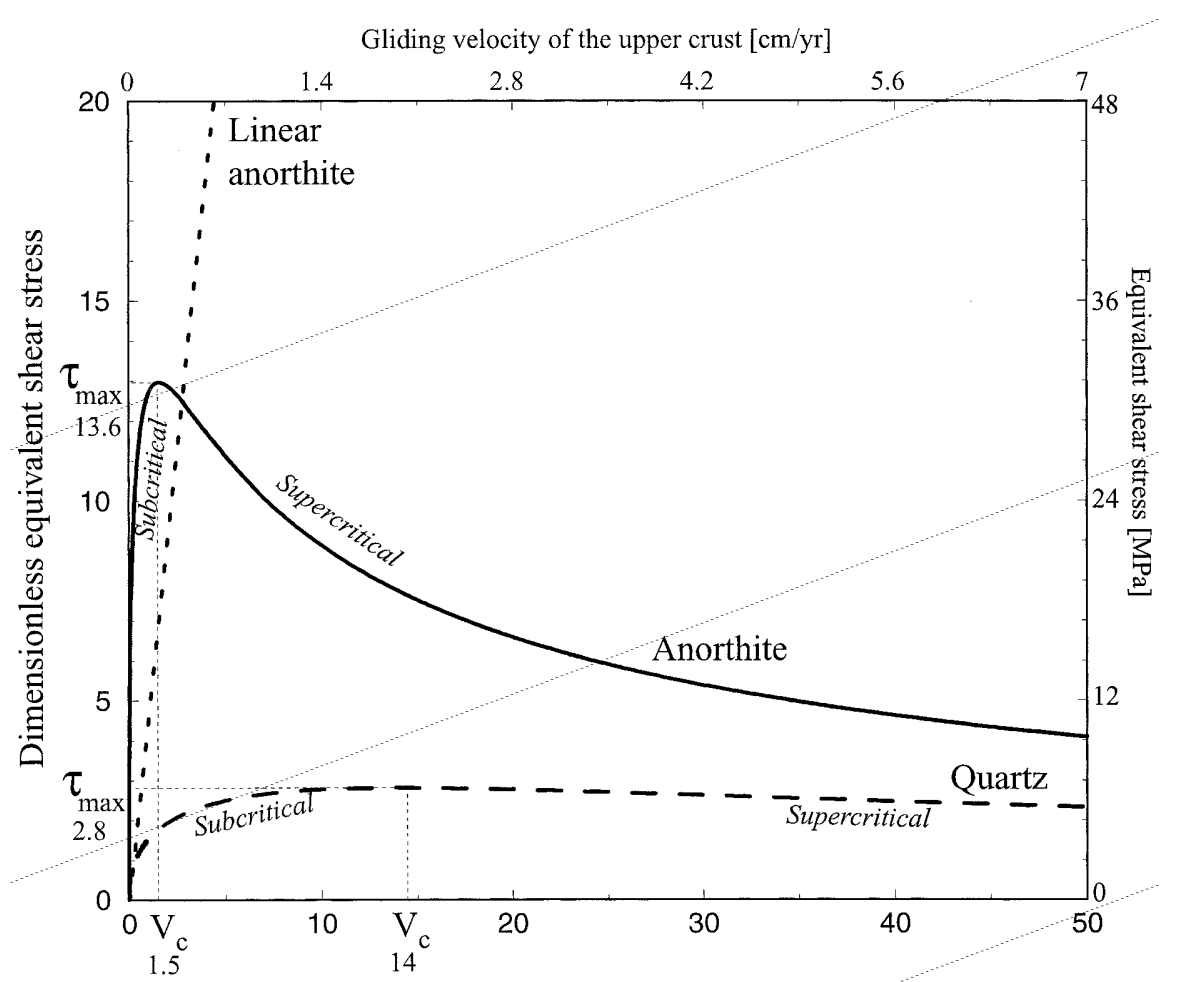

Dimensionless gliding velocity of the upper crust decreasing part of the stress-velocity curve is due to the increasing dominance of temperature effects. Following Joseph (1964), we assume without further proof that the subcritical steady-state branch is stable and the supercritical branch unstable for a stress-controlled shear flow. However, all steady-state solutions are stable for velocity control. We thus cannot invoke an instability or a trend for localization at the contact of the upper crust to explain the desired increase in shear stress. This partitioning of the steady-state solutions does not exist for the linear stress-velocity relation obtained with the Newtonian law for anorthite. It is clear from Fig. 5 that this simplified rheology is not appropriate for determining the equivalent shear stress under steady-state conditions and it will not be used to examine the rapid change in the upper crust extension rate studied next. Indeed, the shear stress value predicted with a linear viscous rheology, for a gliding velocity of $10 \mathrm{~cm} \mathrm{year}^{-1}$, is $340 \mathrm{MPa}$, overestimating the strength of the lower crust. Comparing now the two non-Newtonian viscous materials, one observes that the maximum value of the dimensionless equivalent shear stress, $\tau \max$, is larger for anorthite (13.6) than for quartz (2.8). This difference, which indicates that anorthite, as expected, provides more strength to the lower crust than quartz, is due to the larger value of the stress exponent $n$ in Eq. 21 which controls the strain-rate sensitivity. Note, however, that the dimensionless critical gliding velocity $V \mathrm{c}$ is larger for quartz (14) than for anorthite (1.5). This is due to the smaller value of the Arrhenius constant $\beta r$ for the temperature dependence of quartz (see Table 2).

The last point of discussion in this subsection concerns the physical relevance of these steady states for our continental crust model. The typical values of the dimensionless gliding velocities for the upper crust range from 0 to 50 , corresponding to a velocity of up to $7 \mathrm{~cm} \cdot$ year $^{-1}$. Comparing $V \mathrm{c}$ to this maximum, quartz is expected to be either in its subcritical or supercritical regime, whereas anorthite should be in a supercritical steady flow. Anorthite appears to be the most interesting material for studying transient flow and the variation of the shear stress for reasonable shearing velocity $\left(1.5 \mathrm{~cm}\right.$ year $^{-1}$ in the Gulf of Corinth, Greece, for example) but the two minerals compared so far will also be studied next.

Having described the stationary solutions, we now turn our attention to the transient regime resulting from a rapid change in extension rate of the upper crust.

\section{Transient regime}

The time evolution of the velocity and stress are presented in Fig. 6. The initial conditions of the calculations are always a steady state found on the equilibrium curves of Fig. 5 and also presented in Fig. 6. The imposed velocity at the upper crust contact is first increased linearly in time from its initial value and 
then held constant once the selected value is attained. The time lapse for this velocity change ranges from 1,400 years $(1.4 \mathrm{ka})$ to 1.4 million years $(1400 \mathrm{ka})$. These two extremes must bound the period during which the velocity changed drastically in the Gulf of Corinth, Greece, for example. The final velocity is always set to a dimensionless value of 50 , corresponding to $7 \mathrm{~cm} \cdot \mathrm{year}^{-1}$.
For quartz (Fig. 6a) the initial steady state is subcritical $(V=5)$ and the velocity is thus increased by an order of magnitude. The final shear stress $(\tau=7.1$, corresponding to $17 \mathrm{MPa}$ ) found once the velocity has reached its new value is 2.5 times larger than the maximum value of all steady states. It is also the largest for the fastest rate of change of the velocity. Note the small difference in shear stress increase between 1.4 and $14 \mathrm{ka}$ which could indicate the existence of an
Fig. 6 Equivalent shear stress enhancement due to the rapid change in velocity at the boundary for quartz (a) and anorthite (b). a For quartz, the steady-state initial condition (thin solid curve) is in the subcritical field $(V=5)$, and the rates of change in the velocity are $1.4 \mathrm{ka}$ (dotted curve), $14 \mathrm{ka}$ (dashed curve), $140 \mathrm{ka}$ (long-dashed curve) and $1400 \mathrm{ka}$ (solid curve), as shown inset. The results with the dislocation creep deformation mechanism alone are plotted with the dotted-dashed curve. For anorthite, the initial conditions are in the supercritical field $(V=5)$, with the same conventions for the different rates of change in velocity

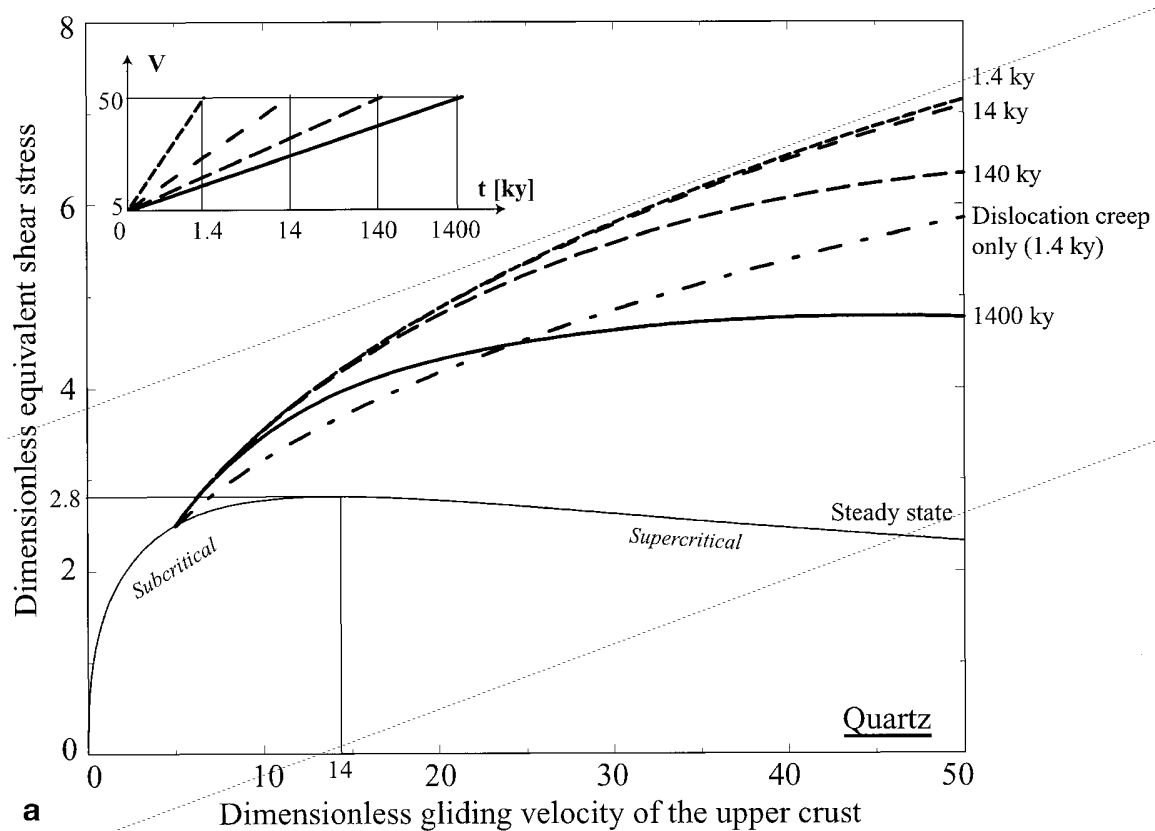

a

Dimensionless gliding velocity of the upper crust

Gliding velocity of the upper crust [ $\mathrm{cm} / \mathrm{yr}]$

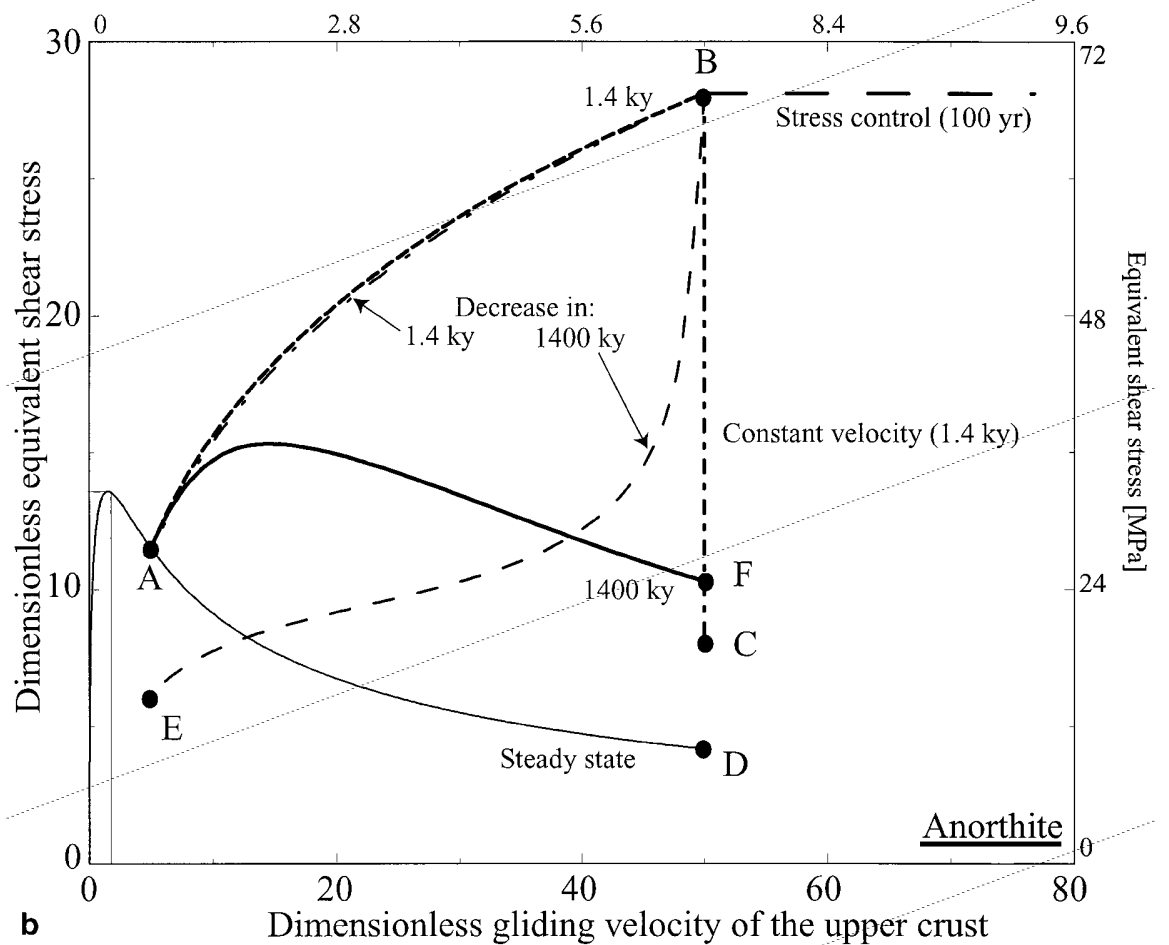


upper bound in shear stress for a given change in velocity. This maximum stress increase appears to be well approximated as soon as the loading time is less than $0.1 \%$ of the characteristic time of our problem (14 My, Table 1 ). Consequently, the upper bound for the shear stress change must be controlled by the strain-rate sensitivity of the flow. Also plotted in Fig. 6a is the stress increase obtained for quartz with dislocation creep as the only deformation mechanism. The shear stress enhancement is then $15 \%$ lower than the result obtained with the two mechanisms, justifying the introduction of diffusion creep in the rheology of the lower crust material advocated here.

The initial steady state selected for anorthite is on the supercritical branch, point A of Fig. 6b. The increase in imposed velocity of the upper crust by an order of magnitude leads to an increase in the equivalent shear stress by factor of up to 2.5 , point B ( $\tau=28$, corresponding to $67 \mathrm{MPa}$ ). Again, this factor is found to attain a maximum value as soon as the loading time becomes negligible compared to the characteristic time of the problem dictated by heat conduction. Note that with a loading time of $1,400 \mathrm{ka}$, which is one tenth of the characteristic conduction time, a shear stress softening occurs during the velocity increase, due to temperature effects (see point F). It is then the steady-state solution at point $\mathrm{D}$ which acts as a stable attractor. The transient stress-velocity curve would be the portion of the steady-state curve between points $\mathrm{A}$ and $\mathrm{D}$ if the velocity change occurs during a time lapse of the same order as or larger than the characteristic time for conduction. The role of the grain size during this transient period will be discussed at a later stage.

To confirm our interpretation of the stability of the steady states, a stress-controlled and a velocity-controlled test were performed once point B was reached. For stress control, the velocity increases at a fast rate, which is typical of a runaway instability. For a constant velocity, the shear stress drops towards the steady-state value at point $\mathrm{D}$ and reaches point $\mathrm{C}$ after only $1.4 \mathrm{ka}$. This result illustrates the stability of the equilibrium in a velocity-controlled setup.

Another series of calculations is performed during which the imposed velocity is reduced in 1.4 or $1,400 \mathrm{ka}$ down to its original value once point $\mathrm{B}$ has been reached. For a loading time of less than $0.1 \%$ of the conduction time, the unloading path (B to $\mathrm{A}$ ) is close to the loading path (A to B) in the absence of any softening effect (no temperature softening or grain size evolution, as will be shown next). However, for a slow unloading time (points B to E), a drastic shear stress softening occurs: the final shear stress at point $\mathrm{E}$ is $45 \%$ smaller than the shear stress at $\mathrm{A}$. This result is difficult to explain without presenting the evolution in grain-size distribution and is thus clarified next.

The grain-size distributions at the final stage of the computations discussed above are presented in Fig. 7a,
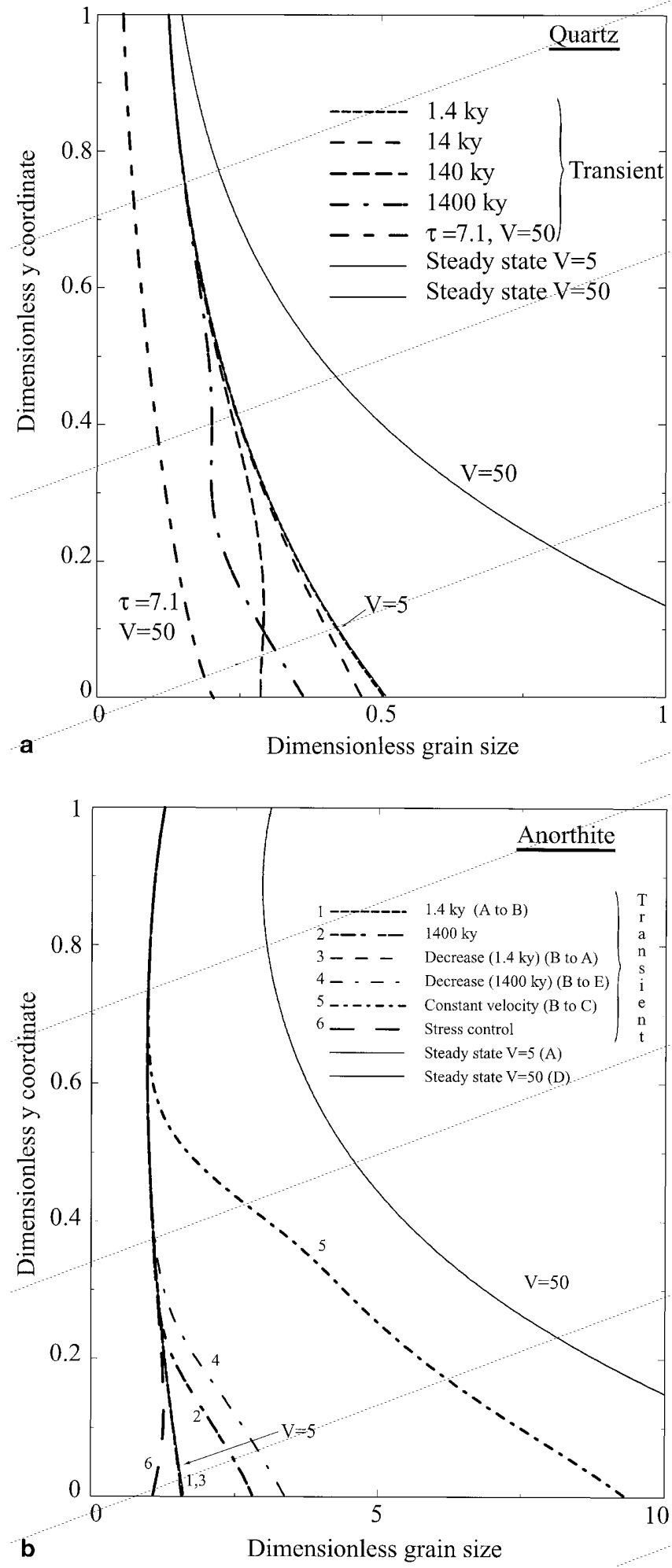

Fig. 7 Grain size profiles through the lower crust during the rapid change in velocity at the boundary. These results correspond to the final step of the tests presented in Fig. 6, with the same conventions, for quartz (a) and anorthite (b) 
b for quartz and anorthite, respectively. The first observation for the two minerals of interest is the absence of any change in grain size in the top $40 \%$ of the lower crust. This is due to the negligible strain rate and the low temperature at these depths, as seen in Fig. 4a, b.

For quartz, the fastest rate of change in velocity shown in Fig. 6a does not modify the grain size distribution: the curve in Fig. 7a obtained for $1.4 \mathrm{ka}$ is close to the initial steady-state distribution $(V=5)$. The grain size is found to decrease, especially close to the Moho, for longer time lapses of velocity change. This result is counter-intuitive if one compares the steadystate value of the grain size for $V=5$ and $V=50$. The difference in grain size $(d-D)$, during the evolution from $V=5$ to $V=50$, is then first negative and, according to Eq. 23, the rate of change of the grain size should be positive. On the contrary, this rate is negative, leading to the grain-size reduction. To understand this apparent discrepancy, the exact definition of the grain-size attractor should be recalled (see 'Dimensional analysis'). The grain size which acts as an attractor is defined by the equality between the amount of the strain rate due to dislocation creep and diffusion creep and thus does not account for the long-term time evolution of the strain rate and temperature. The exact value of this grain size for a velocity of 50 and the corresponding stress of 7.1 found in Fig. 6a is also plotted in Fig. 7a. The grain-size distribution thus predicted reveals that the term $(d-D)$ of Eq. (24) is first positive, explaining the initial negative value of $\dot{d}$. If the velocity is held constant once a velocity of 50 is reached the $D$ values evolve towards the steady value for that velocity, changing the sign of the term $(d-D)$. The factor $\dot{d}$ will thus change sign and the grain size will evolve towards the steady-state value $V=50$.

This second stage of the grain size evolution is clearly seen in Fig. 7b, corresponding to anorthite, and to the time evolution described above from Fig. $6 \mathrm{~b}$. For example, curve 5 in Fig. 7b, obtained for a velocity held constant once point B of Fig. $6 \mathrm{~b}$ is reached, shows how the grain-size distribution has evolved towards the steady-state solution for $V=50$ after $1.4 \mathrm{ka}$. The only curve of Fig. $7 \mathrm{~b}$ where the grain size decreases is the one obtained for a stress control test started from point B (curve 6). In that instance, no steady-state solution acts as an attractor. Also, the fast loading from point $\mathrm{A}$ to $\mathrm{B}$ does not affect the grain size (curve 1). Similarly, the fast unloading from B to A does not change the grain size, explaining the absence of any hysteresis on these curves in Fig. $6 \mathrm{~b}$ (curve 3). If the rate of unloading is lower, the final stress state is at point $\mathrm{E}$ and the difference in stress can now be explained as follows. During the first part of the unloading, the grain size (curve 4) has time to increase towards the steady-state value defined by the steady solution for $V=50$ (point $\mathrm{D}$ ). Once point $\mathrm{E}$ is reached, the steady grain size of point $\mathrm{A}$ will act as an attractor but time must be spent to let the grain size evolve towards this new steady state. The above discussion reveals the history dependence of the grainsize distribution. As a final illustration, one should compare curves 5 and 2 of Fig. 7b, corresponding to points $\mathrm{C}$ and $\mathrm{F}$. Points $\mathrm{C}$ and $\mathrm{F}$ are close in the stressvelocity space but the grain-size distributions are very different. The main reason for this is that the stress was much larger in the path $\mathrm{A}-\mathrm{B}-\mathrm{C}$ than along $\mathrm{A}$ to F. The grain-size attractor, $D$, given by Eq. (24), is a function of the stress and thus was different during the two histories.

To summarize this discussion on the evolution of grain size, it should be stressed that the fact that the grain size decreases during a phase of increase in the velocity of the upper-crust proves that the deformation mechanism dislocation creep is definitely activated during that period in the lower crust. However, during the phase when the velocity is constant in time it is the deformation mechanism diffusion creep which dominates. This partition between the activation of the two mechanisms in the lower crust appears to have been unnoticed so far in the literature.

Now that we have an idea of the increase in magnitude of the equivalent shear stress to be expected during a rapid change in extension rate of the upper crust, we can use this information to assess whether brittle deformation mechanisms could be activated at the brittle-ductile transition. For this purpose, the shear stress attained during transient flow is plotted in a normal stress-shear stress diagram (Fig. 8) typical for a Mohr-Coulomb criterion, for the lower crust. Various values of the friction coefficient between 0.1 and 1 (Brace and Kohlstedt 1980) have been selected and the normal stress is defined by the overburden weight. The classical range used for the friction coefficient (between 0.6 and 1) is much too large for our shear stress enhancement to be sufficient for shear failure to occur according to a Mohr-Coulomb criterion. Failure could only take place for anorthite if the friction coefficient was much lower, of the order of 0.2 . Such a value may end up being realistic if pore fluid effects are accounted for (Brace and Kohlstedt 1980). This interpretation remains to be confirmed by laboratory tests. For a friction coefficient of 0.2, failure of anorthite takes place only in the first $3 \mathrm{~km}$ of the lower crust, just below the brittle-ductile transition. This result confirms that the strain localization observed at the brittle-ductile transition could result from brittle deformation mechanisms which are activated at that depth. Note that for quartz failure never occurs, even with a friction coefficient as low as 0.1 .

\section{Conclusions}

Field evidence suggests the existence at the brittleductile transition of ductile shear zones leading to detachment planes associated with brittle deformation. 


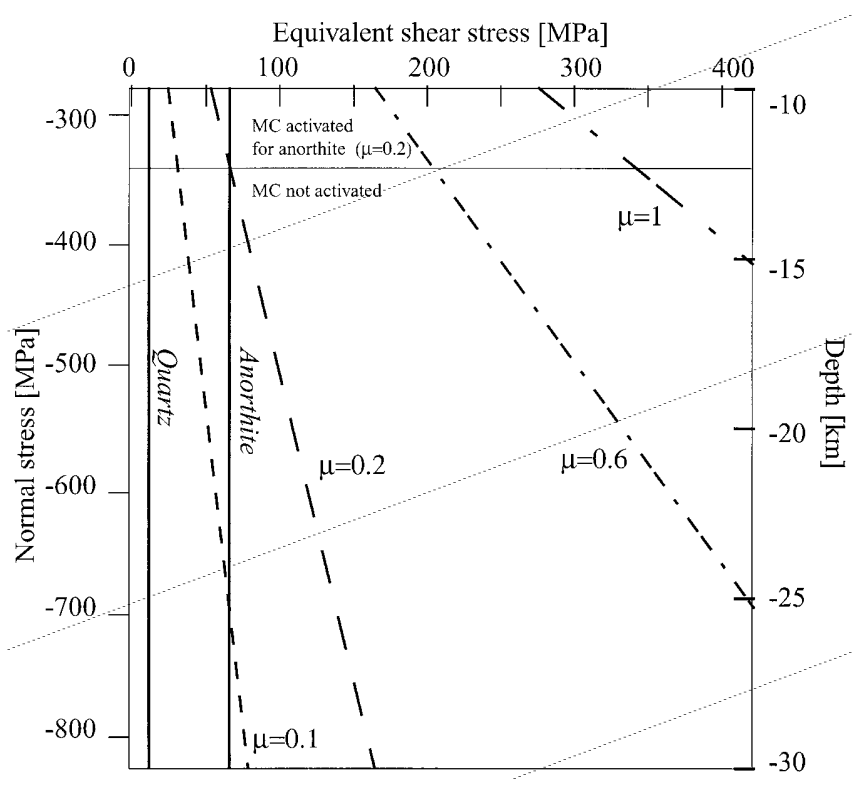

Fig. 8 Normal stress (MPa) and equivalent shear stress (MPa) relation according to the Mohr Coulomb criterion with zero cohesion and different values of the friction coefficient $\mu$ : 0.1 , $0.2,0.6$ and 1. The maximum shear stress detected during the transient analysis for quartz and anorthite are also plotted in the diagram as vertical lines

The activation of these brittle deformation mechanisms requires an equivalent shear stress of the same order as the mean stress. To document the possibility of the equivalent shear stress increasing to such a level while remaining compatible with the viscous flow of the lower crust, a simple 1D model of the crust has been proposed. This model corresponds to a vertical section through the continental crust in extension and thus consists of an upper crust gliding rigidly over the lower crust, deforming in an overall simple shear mode. A non-Newtonian rheology is adopted for the material flow in the lower crust, adding to the classical strain-rate and temperature sensitivity a dependence on the grain size. The rheological law results from the coupling in series of dislocation creep and diffusion creep. The solution to the initial and boundary value problem was obtained by applying the finite-element method to the thermo-mechanical flow for both steady and transient conditions.

The numerical results are summarized as follows. During a rapid increase in the velocity at the contact of the upper crust from a steady-state value, the deformation mechanism dislocation creep is activated and leads to a decrease in grain size. If this velocity is then held constant or is reduced, diffusion creep dominates and leads to grain growth. During a cycle, the rate at which the velocity is changed has a drastic influence on both the stress and the grain size. A rapid cycle is conducive to a sharp increase in stress which in turn controls the level of activity of the grain size change. The current grain size distribution thus has a strong history dependence. This result is obtained with a simple evolution law which has the merit of introducing a second characteristic time into the problem.

It should also be mentioned that there is a maximum change in stress for a given velocity change which is well approximated as soon as the time lapse of this change is less than $1 \%$ of the characteristic conduction time over the whole crust. This change in stress is thus controlled by the strain-rate sensitivity of the material. The maximum magnitudes of the equivalent shear stress for anorthite and quartz are found to reach 67 and $17 \mathrm{MPa}$, respectively. For anorthite, this magnitude is sufficient to activate brittle deformation mechanisms if their onset is controlled by a Mohr-Coulomb criterion with a friction coefficient of 0.2. This low value of the friction coefficient appears to be justified at the depth of $10 \mathrm{~km}$ if fluid effects are invoked (Brace and Kohlstedt 1980).

The main conclusion of this paper on the activation of brittle deformation mechanisms is reached in a twostep argument. First, a rheology typical of ductile materials is invoked to compute a stress change and, secondly, the new stress is applied to a Mohr-Coulomb criterion. To improve on this reasoning, one should propose a rheological model which combines the ductile and the brittle deformation mechanisms. The solution of a boundary value problem similar to the one studied here would then provide information on the activation of the brittle mechanisms. Furthermore, if these brittle mechanisms have destabilizing effects, the final solution should exhibit the tendency for strain localization which marks the onset of a shear zone at the brittle-ductile transition. The results presented in this paper give us a certain confidence that such a research direction deserves further attention.

Acknowledgements The motivation to account for the destabilizing influence of grain-size reduction during recrystallization came from a discussion with Professor C.J. Spiers and Dr. H. de Bresser, both at the University of Utrecht, The Netherlands. We wish to thank J. Braun and M.R. Drury for providing considerable help in improving the manuscript.

\section{References}

Armijo R, Meyer B, King GCP, Rigo A, Papanastassiou D (1996) Quaternary evolution of the Corinth Rift and its implications for the Late Cenozoic evolution of the Aegean. Geophys J Int 126:11-53

Avigad D, Garfunkel Z (1989) Low-angle faults above and below a blueschist belt: Tinos Island, Cyclades, Greece. Terra Nova 1:182-187

Braun J, Chéry J, Poliakov A, Mainprice D, Vauchez A, Tomassi A, Daignières M (1999) A simple parametrization of strain localization in the ductile regime due to grain size reduction: A case study for olivine. J Geophys Res 104(B11):25, 167-25, 181

Brace WF, Kohlstedt DL (1980) Limits on lithospheric stress imposed by laboratory experiments. J Geophys Res 85 (B11):6248-6252 
Brun JP, Cobbold PR (1980) Shear heating and thermal softening in continental shear zones: a review. J Struct Geol $2: 149-158$

Byerlee JD (1978) Friction of rocks. Pure Appl Geophys 116:615-626

Christie JM, Ord A, Koch PS (1980) Relationship between recrystallized grain size and flow stress in experimentally deformed quartzite. EOS Trans AGU 61:377

Davis GH (1983) Shear-zone model for the origin of metamorphic core complexes. Geology 11:342-347

de Bresser JHP, Peach CJ, Reijs JPJ, Spiers CJ (1998) On dynamic recrystallization during solid state flow: effects of stress and temperature. Geophys Res Lett 25 (18):3457-3460

Derby B, Ashby MF (1987) On dynamic recrystallization. Scripta Met 21:879-884

Drury MR, Humphreys FJ, White SH (1985) Large strain deformation studies using polycrystalline magnesium as a rock analogue. Part II: dynamic recrystallisation mechanisms at high temperatures. Phys Earth Plan Int 40:208-222

Evans B, Kohlstedt DL (1995) Rheology of rocks. In: Ahrens TJ (ed) Handbook of physical constants part 3. Rock physics and phase relations. AGU, Washington, DC, pp 148-165

Frost HJ, Ashby MF (1982) Deformation mechanism maps. Pergamon Press, Oxford, $166 \mathrm{pp}$

Gautier P, Brun JP (1994a) Crustal-scale geometry and kinematics of late-orogenic extension in the central Aegean (Cyclades and Evvia island). Tectonophysics 238:399-424

Gautier P, Brun JP (1994b) Ductile crust exhumation and extensional detachments in the central Aegean (Cyclades and Evvia islands). Geodin Acta 7 (2):57-85

Gueydan F (2001) Etude de la localisation de la déformation à la transition fragile-ductile de la croûte continentale soumise à une extension. Thesis, Université Pierre et Marie Curie, Paris

Haag AC (1944) Heat effects in lubricating films. J Appl Mech A:72-76

Handy MR (1989) Deformation regimes and the rheological evolution of fault zones in the lithosphere: the effects of pressure, temperature, grain size and time. Tectonophysics 163:119-152

Hopper JR, Buck WR (1993) The initiation of rifting at constant tectonic force: role of diffusion creep. J Geophys Res 98(B9):16,213-16,221

Jin D, Karato S-I (1998) Mechanisms of shear localization in the continental lithosphere: inference from the deformation microstructures of peridotites from the Ivrea zone, northwestern Italy. J Struct Geol 20:195-209

Jolivet L, Patriat M (1999) Ductile extension and the formation of the Aegean Sea. In: Durand B, Jolivet L, Horvàth L, Séranne $M$ (eds) The Mediterranean basins: Tertiary extension within the Alpine orogen. Geol Soc Spec Publ, pp 427-456

Joseph DD (1964) Variable viscosity effects on the flow and stability of flow in channels and pipes. Phys Fluids 7:1761-1771

Kameyama M, Yuen DA, Fujimoto H (1997) The interaction of viscous heating with grain-size dependent rheology in the formation of localized slip zones. Geophys Res Lett 24:2523-2526

Kirby SH (1985) Rock mechanics observations pertinent to the rheology of the continental lithosphere and the localization of strain along shear zones. Tectonophysics 119:1-27

Koch PS, Christie JC, Ord A, George RPJ (1989) Effect of water on the rheology of experimentally deformed quartzite. J Geophys Res 94(B10):13975-13996

Laigle M, Hirn A, Sachpazi M, Roussos N (2000) North Aegean crustal deformation: an active fault imaged to $10 \mathrm{~km}$ depth by reflection seismic data. Geology 28:71-74
Le Pichon X, Chamot-Rooke N, Lallemant SL, Noomen R, Veis $G$ (1994) Geodetic determination of the kinematics of central Greece with respect to Europe: implications for eastern Mediterranean tectonics. J Geophys Res B 100:12,675-12,690

Leroy YM, Molinari A (1992) Stability of steady states in shear zones. J Mech Phys Solids 40:181-212

Lister GS, Davis GA (1989) The origin of metamorphic core complexes and detachment faults formed during Tertiary continental extension in the northern Colorado River region, U.S.A. J Struct Geol 11:65-94

Lister GS, Banga G, Feenstra A (1984) Metamorphic core complexes of cordilleran type in the Cyclades, Aegean Sea, Greece. Geology 12:221-225

Melosh HJ (1976) Plate motion and thermal instability in the asthenosphere. Tectonophysics 35:363-390

Melosh HJ (1990) Mechanical basis for low-angle normal faulting in the Basin and Range province. Nature 343:331-335

Mercier JC, Anderson DA, Carter NL (1977) Stress in the lithosphere: inference from the steady state flow of rocks. Pure Appl Geophys 115:199-226

Miller EL, Gans PB, Garing J (1983) The snake range decollement: an exhumed mid-tertiary ductile-brittle transition. Tectonics 2:239-263

Patriat M, Jolivet L (1998) Post-orogenic extension and shallowdipping shear zones, study of a brecciated decollement horizon in Tinos (Cyclades, Greece). C R Acad Sci Paris Earth Planet Sci 326:355-362

Poirier JP (1980) Shear localization and shear instability in materials in the ductile field. J Struct Geol 2:135-142

Rigo A, Lyon-Caen H, Armijo R, Deschamps A, Hatzfeld D, Makropoulos K, Papadimitriou P, Kassaras I (1996) A microseismicity study in the western part of the Gulf of Corinth (Greece): implications for large-scale normal faulting mechanisms. Geophys J Int 126:663-688

Rutter EH, Brodie KH (1995) Mechanistic interactions between deformation and metamorphism. Geol J 30:227-240

Schubert G, Yuen DA (1978) Shear heating instability in the Earth's upper mantle. Tectonophysics 50:197-205

Shelton G (1981) Experimental flow laws for crustal rocks. EOS 62(17):396

Shimizu I (1998) Stress and temperature dependance of recrystallized grain size: A subgrain misorientation model. Geophys Res Lett 25:4237-4240

Turcotte DL, Schubert G (1982) Geodynamics. Applications of continuum physics to geological problems. Wiley, New York, $450 \mathrm{pp}$

Twiss RJ (1977) Theory and applicability of a recrystallized grain size paleopiezometer. Pure Appl Geophys 115:227-244

Wang Z, Dresen G, Wirth R (1996) Diffusion creep of finegrained polycrystalline anorthite at high temperature. Geophys Res Lett 23 (22):3111-3114

Wernicke B (1981) Low-angle normal faults in the Basin and Range province: nappe tectonics in an extending orogen. Nature 291:645-648

Wernicke B (1985) Uniform-sense normal simple shear of the continental lithosphere. Can J Earth Sci 22:108-125

Wernicke B (1992) Cenozoic extensional tectonics of the U.S. cordillera. In: Burchfiel BC, Lipman PW, Zoback ML (eds) The Cordilleran Orogen: Conterminous U.S. Geological Society of America, Boulder, pp 553-581

Wernicke B, Burchfiel BC (1982) Modes of extensional tectonics. J Struct Geol 4:105-115

Yuen DA, Schubert G (1977) Asthenospheric shear flow: thermally stable or unstable? Geophys Res Lett 4:503-506 